ISSN 1420-3049

www.mdpi.com/journal/molecules

Article

\title{
Simplified Synthesis of Isotopically Labeled 5,5-Dimethyl-pyrroline $\mathrm{N}$-Oxide
}

Fabian Leinisch ${ }^{1}, *$, JinJie Jiang ${ }^{1}$, Leesa J. Deterding ${ }^{2}$ and Ronald P. Mason ${ }^{1}$

1 Laboratory of Toxicology and Pharmacology, National Institute of Environmental Health Sciences, National Institutes of Health, 111 TW Alexander Drive, Research Triangle Park, NC 27709, USA

2 Laboratory of Structural Biology, National Institute of Environmental Health Sciences, National Institutes of Health, 111 TW Alexander Drive, Research Triangle Park, NC 27709, USA

* Author to whom correspondence should be addressed; E-Mail: leinischf@niehs.nih.gov; Tel.: +1-919-541-7574; Fax: +1-919-541-1043.

Received: 25 July 2011; in revised form: 14 September 2011 / Accepted: 21 September 2011 / Published: 10 October 2011

\begin{abstract}
Dimethylpyrroline $N$-oxide $\left({ }^{15} \mathrm{~N}\right)$ and 5,5-di(trideuteromethyl)pyrroline $\mathrm{N}$-oxide were synthesized from the respective isotopically labeled 2-nitropropane analogs obtained from the reaction of sodium nitrate with 2-halopropanes. This facile, straightforward process allows synthesizing isotopically labeled DMPO analogs in a 4-step reaction without special equipment.
\end{abstract}

Keywords: spin trap; isotopic labeling; DMPO

\section{Introduction}

Nitrone spin traps such as the most commonly used 5,5-dimethylpyrroline $N$-oxide (DMPO) are important reagents for the detection of free radicals by means of ESR spin trapping [1]. For certain mass spectrometry experiments or to investigate the fidelity of spin trapping, it is helpful to use isotopically labeled spin traps.

The di(trideuteromethyl) analog of DMPO with its mass shift of +6 compared to unlabeled DMPO can be used for dual spin-trapping mass spectrometry experiments. Here, spin traps labeled with stable isotopes $\left({ }^{2} \mathrm{H},{ }^{15} \mathrm{~N}\right.$ or $\left.{ }^{13} \mathrm{C}\right)$ are utilized to simplify the interpretation of mass spectrometry experiments $[2,3]$. With equal amounts of the labeled and unlabeled spin trap present, adducts of the 
trapped radicals will appear as ion pairs in the mass spectrum (with the mass differences depending on the isotopes incorporated in the spin trap and on the charge state of the ion). This facilitates and clarifies the identification of radical-derived analytes.

The ${ }^{15} \mathrm{~N}$ analog can be used to unambiguously determine the susceptibility of a particular spintrapping experiment to the Forrester-Hepburn artifact in an ESR experiment [4]. A Forrester-Hepburn artifact is the result of nucleophilic attack of the radical precursor on the spin trap with subsequent oxidation to the identical nitroxide radical as derived from genuine spin trapping. It is difficult to distinguish between nucleophilic attack and free-radical trapping, with normal chemical and biological control experiments being of no use. Timmins et al. reported a method based on spin traps with different isotopes at the $\alpha$ - or $\beta$-positions to the nitrogen of the spin trap [4]. The substrate is preincubated with a spin trap (first isotope), and then the spin trap labeled with the second isotope is added simultaneously with the initiation of free radical formation. Because the ESR signals are different, the origin of the signal can be determined as artifact or genuine signal. Employing that technique, we were able to identify the $\mathrm{DMPO} /{ }^{\circ} \mathrm{CN}$ radical, supposedly generated by horseradish peroxidase and hydrogen peroxide, as an artifact (unpublished data).

The classical synthesis of DMPO, as reported by Janzen et al. [5], is based on the synthesis of pyrrolines [6]. Later, Le et al. [7] published a synthesis of $2-{ }^{14} \mathrm{C}-\mathrm{DMPO}$ that avoided the direct Michael reaction of nitropropane with methyl acrylate, thereby improving the low yield and eliminating the difficult purification of this step. For the synthesis of isotopically labeled DMPO, Pou et al. [8] published an effective method starting from ${ }^{15} \mathrm{~N}$-hydroxylamine, which involved the use of hydrogen gas in an autoclave as well as a reaction with ozone derived from an ozone generator. We have developed a more facile synthetic pathway for the synthesis of DMPO based on ${ }^{15} \mathrm{~N}$-sodium nitrite or 2-bromopropane (D7) as the isotopically labeled starting material. The intermediate 2-nitropropane was prepared in a one-step reaction according to the reaction principle described by Kornblum et al. [9]. This principle has been used for nitrone spin trap synthesis [10]. Nitropropane was then used for a DMPO synthesis similar to that of Le et al. [7] (Scheme 1).

Scheme 1. Pathway of DMPO analog synthesis.
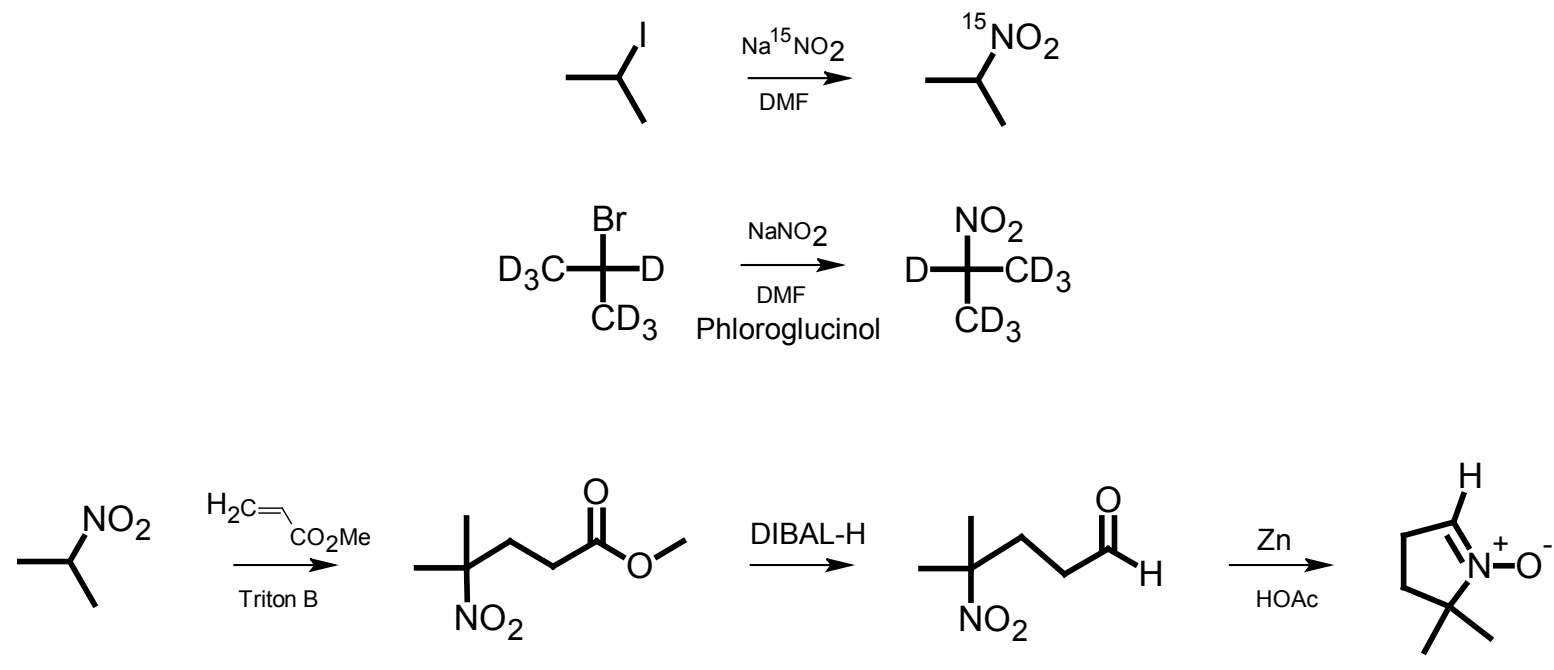


\section{Results and Discussion}

\subsection{2-Nitropropane}

The synthesis of 2-nitropropane can be accomplished directly by nitration of 2-halopropanes with sodium nitrite [9]. With 2-iodopropane, the reaction is carried out in dry DMF in the presence of urea. For the slower reacting 2-bromopropane, a longer reaction time and the presence of phloroglucinol as a nitrite ester scavenger is required.

To synthesize ${ }^{15} \mathrm{~N}$-DMPO, 2-iodopropane was used in slight excess in the absence of phloroglucinol because phloroglucinol did not increase the yields with respect to the ${ }^{15} \mathrm{~N}$-nitrite. The nitrite forms the nitro compound and, as a byproduct in a slow process, the nitrite ester. In an undesired reaction, the latter can react with already formed nitropropane, but the nitrite ester can be removed with phloroglucinol [9]. However, under the chosen conditions, the formation of the nitrite ester is not the limiting factor for the yield. After purification by vacuum distillation, the yield of ${ }^{15} \mathrm{~N}$-2-nitropropane was 35\%. Perdeuterated 2-nitropropane (D7) was synthesized from 2-bromopropane (D7) in the presence of phloroglucinol since this was more economical than employing the corresponding deuterated iodo-compound. The reaction gave perdeuteronitropropane, formed with $27 \%$ yield after purification. The yields are not very high for one-step reactions, but still result in a higher overall yield of 2-nitropropane than a multistep process (e.g., Gabriel-synthesis of the corresponding phthalate, cleavage of the 2-propylamine [11] and subsequent oxidation by ozone, which can induce isomerization).

\subsection{Methylnitrovaleric Acid Methyl Ester}

In order to avoid the reported problems of the direct aldehyde synthesis via the Michael reaction [5], we chose, instead, the conditions described by Moffett [12] to optimize the yield with respect to the nitropropane. The yield of ${ }^{15} \mathrm{~N}$-nitropropane was $51 \%$ and the yield of the 1,1,1,3,3,3-hexadeutero-2nitropropane was $80 \%$, which was comparable to that reported in the literature [12].

\subsection{Methylnitropentanal}

The corresponding pentanal was formed by reduction with diisobutylaluminum hydride, as described by Le et al.[7]. Some experimental details of the protocol were modified according to [13]. In order to achieve a selective reduction to the aldehyde with minimal further reduction to the alcohol, which is difficult to remove once formed, the bath temperature should be maintained at $-90{ }^{\circ} \mathrm{C}$ during the reaction. The use of wet silica gel allows the quenching procedure to be carried out at the reaction temperature [13]. The reaction gave yields of $58 \%$ for the hexadeutero- and $74 \%$ for the

${ }^{15} \mathrm{~N}$-compound, which is in the expected range for diisobutylaluminum hydride reductions [13].

\subsection{DMPO}

The final step was carried out as described in the literature [7]. The yield of DMPO was 15\% with both analogs. In preliminary experiments, the activation of zinc or variations of the zinc equivalents did not improve the yield to $60 \%$, as previously reported [14]. In our hands, we obtained $c a$. $15-20 \%$ (as also reported by Le et al. [7]). In retrospect, for future syntheses it may be beneficial to protect the 
aldehyde as dioxolane before the reduction step [5] because Rosen et al. also reported a low yield for the direct reaction [15].

The synthesized DMPO analogs and ${ }^{14} \mathrm{~N}-\mathrm{DMPO}$ were analyzed using high mass resolution mass spectrometry $(\mathrm{Rs}>10,000)$. The protonated molecular ion of each analog was observed and the resulting exact mass measurement was determined. The resulting $\mathrm{M}+\mathrm{H}^{+}$ions observed for each DMPO analog were as follows: DMPO $(\mathrm{M}+\mathrm{H})^{+}$ion of $m / z 114.0915$ (theoretical $\mathrm{M}+\mathrm{H}^{+}=114.0919$ ), ${ }^{15} \mathrm{~N}-\mathrm{DMPO}(\mathrm{M}+\mathrm{H})^{+}$ion of $m / z 115.0882$ (theoretical $\mathrm{M}+\mathrm{H}^{+}=115.0889$ ), and ${ }^{6} \mathrm{D}-\mathrm{DMPO}(\mathrm{M}+\mathrm{H})^{+}$ion of $m / z 120.1282$ (theoretical $\mathrm{M}+\mathrm{H}^{+}=120.1295$ ). According to their elemental compositions, these exact mass measurements correspond to mass accuracies of $3.5 \mathrm{ppm}, 6.1 \mathrm{ppm}$, and $10.8 \mathrm{ppm}$, respectively. In addition, similar fragmentations of each analog were observed.

With a spin-trapping experiment, the coupling constants of the respective hydroxyl radical adducts were determined. A strong signal was detected with both analogs (Figures 1a,d). With the di(trideuteromethyl) analog, a signal with similar coupling constants and the same intensity as with ${ }^{14} \mathrm{~N}$-DMPO emerged (D6-DMPO: $\mathrm{a}^{\mathrm{N}}=14.97 \mathrm{G}$ and $\mathrm{a}^{\mathrm{H}}=14.77 \mathrm{G} ;{ }^{14} \mathrm{~N}-\mathrm{DMPO}: \mathrm{a}^{\mathrm{N}}=14.96 \mathrm{G}$ and $\mathrm{a}^{\mathrm{H}}=14.76 \mathrm{G}$, not shown. Literature: $\mathrm{a}^{\mathrm{N}}=14.8$ and $\mathrm{a}^{\mathrm{H}}=14,8$ [8]). With the ${ }^{15} \mathrm{~N}$-analog, coupling constants were determined to be $\mathrm{a}^{\mathrm{N}}=20.95 \mathrm{G}$ and $\mathrm{a}^{\mathrm{H}}=14.78 \mathrm{G}$. The change of the nitrogen hyperfine coupling constant is due to the gyromagnetic ratio of ${ }^{15} \mathrm{~N}:{ }^{14} \mathrm{~N}=1.40[16,17]$. In the absence of hydrogen peroxide ( $b$ and e) or iron (c and $\mathrm{f}$ ), no significant signal was detected with either analog.

Figure 1. ESR spin trapping of hydroxyl radicals with $100 \mathrm{mM}{ }^{15} \mathrm{~N}$ - or di(trideuteromethyl) DMPO. Radicals were generated with a Fenton System $\left(100 \mu \mathrm{M} \mathrm{FeSO}_{4}, 200 \mu \mathrm{M} \mathrm{H}_{2} \mathrm{O}_{2}\right.$ in $100 \mathrm{mM}$ phosphate buffer, $\mathrm{pH} 7.4$, with $200 \mu \mathrm{M}$ DTPA). A strong signal was detected with ${ }^{15} \mathrm{~N}$-DMPO (a) as well as with di(trideuteromethyl) DMPO (d). No significant signal was detected without $\mathrm{H}_{2} \mathrm{O}_{2}$ (b and e) or $\mathrm{Fe}^{2+}$ (c and $\left.\mathbf{f}\right)$.
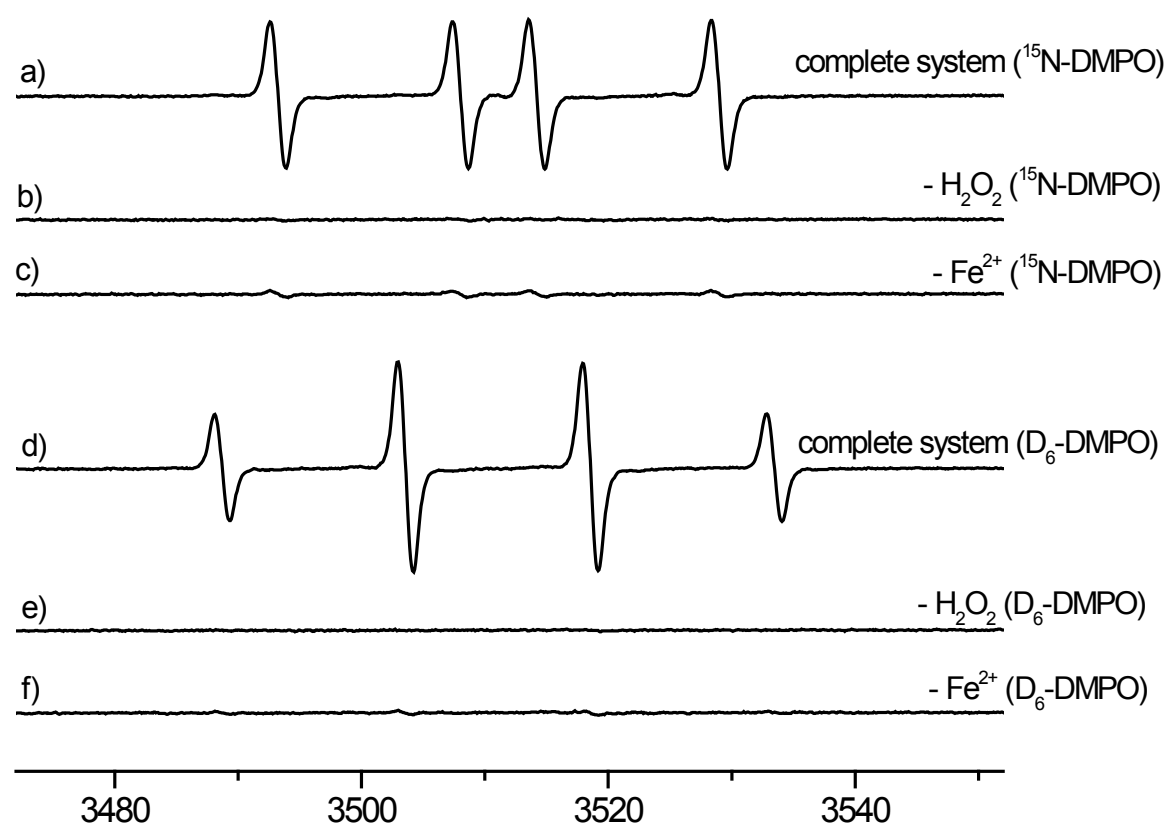

magnetic field / $G$ 


\section{Experimental}

${ }^{15} \mathrm{~N}-\mathrm{NaNO}_{2}$ and 2-bromopropane (D7) were purchased from Cambridge Isotope Laboratories (Andover, MA, USA). Phloroglucinol was purchased from Alfa Aesar (Ward Hill, MA, USA). ${ }^{14} \mathrm{~N}$-DMPO was purchased from Dojindo (Rockville, MD, USA). Other chemicals were purchased from Sigma-Aldrich (St. Louis, MO, USA). Where dry solvents were required, the glassware was oven-dried and a dry argon atmosphere was used. These solvents were purchased as 'anhydrous' grade and handled under air exclusion. ESR spectra were recorded with a Bruker ElexSys E-500 spectrometer with ER 4122SHQ cavity, flow injection electrospray ionization (ESI/MS) analyses were performed with a Waters Q-TOF Premier mass spectrometer. ${ }^{1} \mathrm{H}$ NMR spectra were acquired at $25{ }^{\circ} \mathrm{C}$ on a Varian INOVA 600 spectrometer operating at ${ }^{1} \mathrm{H}$ frequency of $599.763 \mathrm{MHz}$.

\subsection{Synthesis of ${ }^{15}$ N-5,5-Dimethyl-1-pyrroline $N$-oxide}

${ }^{15} \mathrm{~N}$-2-Nitropropane. In a $500 \mathrm{~mL}$ three-neck flask equipped with a magnetic stir bar, septum, Ar supply and a gas bubbler, urea (17 g, $0.28 \mathrm{~mol})$ was dissolved in dry N,N-dimethylformamide (250 mL) under an Ar atmosphere. Then, ${ }^{15} \mathrm{~N}^{-N_{a N O}}$ (10 g, $\left.145 \mathrm{mmol}\right)$ was added and allowed to dissolve. 2-Iodopropane (18 mL; $180 \mathrm{mmol})$ was added and the solution was stirred for $5 \mathrm{~h}$ at room temperature. The reaction was quenched by pouring the reaction mixture into ice water $(300 \mathrm{~mL})$ with diethyl ether $(100 \mathrm{~mL})$. The organic layer was separated and retained, and the aqueous layer was extracted four times with diethyl ether. The combined organic layers were washed twice with sodium thiosulfate solution $(10 \mathrm{wt} \%, 25 \mathrm{~mL})$ followed by washing with saturated sodium bicarbonate solution $(2 \times 100 \mathrm{~mL})$. The organic layer was dried over anhydrous magnesium sulfate, filtered, and the solvent removed with a rotary evaporator to obtain the crude product. The product was purified by vacuum distillation $\left(-80 \mathrm{kPa}, 75{ }^{\circ} \mathrm{C}\right)$ to give $4.63 \mathrm{~g}(51 \mathrm{mmol}, 35 \%)$ of ${ }^{15} \mathrm{~N}$-2-nitropropane. ${ }^{1} \mathrm{H}-\mathrm{NMR}\left(\mathrm{CDCl}_{3}\right)$ : $1.51(\mathrm{~m}, 6 \mathrm{H}), 4.62(\mathrm{~m}, 1 \mathrm{H})$.

${ }^{15} \mathrm{~N}$-4-Methyl-4-nitropentanoic acid methyl ester. To a $100 \mathrm{~mL}$ three-neck flask with magnetic stir bar, condenser and addition funnel, ${ }^{15} \mathrm{~N}$-2-nitropropane (4.63 g, $\left.51 \mathrm{mmol}\right), 1$,4-dioxane $(5 \mathrm{~mL})$ and an aqueous solution of benzyltrimethylammonium hydroxide (Triton B, 40\%, $1 \mathrm{~mL}$ ) were added. The contents were heated to $70{ }^{\circ} \mathrm{C}$ (water bath) with stirring, and methyl acrylate $(4.5 \mathrm{~mL}, 52 \mathrm{mmol}$ ) was added dropwise over $15 \mathrm{~min}$. The temperature was raised and the solution stirred at $85{ }^{\circ} \mathrm{C}$ for $3 \mathrm{~h}$. After cooling to room temperature, the solution was diluted $\left(100 \mathrm{~mL}\right.$ of $\left.\mathrm{H}_{2} \mathrm{O}\right)$ and acidified with diluted hydrochloric acid $(1 \mathrm{M})$. The reaction mixture was then extracted five times with diethyl ether $(100 \mathrm{~mL}$ each). The combined organic layers were washed with water, saturated sodium bicarbonate solution and water again $\left(100 \mathrm{~mL}\right.$ each), then dried over anhydrous $\mathrm{NaSO}_{4}$. The solvent was removed on a rotary evaporator to give the crude product, which was purified by column chromatography on silica gel (hexane:diethyl ether $=1: 1)$ to give $4.62 \mathrm{~g}(26.4 \mathrm{mmol}, 51 \%)$ of ${ }^{15} \mathrm{~N}-4$-methyl-4-nitropentanoic acid methyl ester. An $\mathrm{r}_{\mathrm{f}}$ of 0.33 was found. The product was stored under an argon atmosphere. ${ }^{1} \mathrm{H}-\mathrm{NMR}\left(\mathrm{CDCl}_{3}\right): 1.57(\mathrm{~s}, 3 \mathrm{H}), 1.78(\mathrm{~s}, 3 \mathrm{H}), 2.26(\mathrm{~m}, 2 \mathrm{H}), 2.32(\mathrm{~m}, 2 \mathrm{H})$, 3.67 (s, 3H). 
${ }^{15} \mathrm{~N}$-4-Nitro-4-methyl-1-pentanal. A $500 \mathrm{~mL}$ three-neck flask equipped with a magnetic stir bar, septum, Ar supply and gas bubbler was filled with dry dichloromethane $(125 \mathrm{~mL})$ with the exclusion of air. ${ }^{15} \mathrm{~N}-4$-methyl-4-nitropentanoic acid methyl ester (4.62 g; $\left.26.4 \mathrm{mmol}\right)$ was added, and the solution was cooled down to $-95{ }^{\circ} \mathrm{C}$ with a methanol bath using dry ice initially, then liquid nitrogen for temperature adjustment. Next, $1 \mathrm{M}$ diisobutylaluminum hydride solution in dichloromethane $(29 \mathrm{~mL})$ was added dropwise over $5 \mathrm{~min}$, keeping the temperature below $-90{ }^{\circ} \mathrm{C}$. After $40 \mathrm{~min}$ of stirring at $-95^{\circ} \mathrm{C}$, the solution was quenched by the addition of wet silica gel $(20 \mathrm{~g}$ of silica gel well-mixed with $10 \mathrm{~mL}$ of $\mathrm{H}_{2} \mathrm{O}$ ) while maintaining the reaction mixture at $-95^{\circ} \mathrm{C}$. After $10 \mathrm{~min}$ of stirring at $-95^{\circ} \mathrm{C}$, the cold bath was removed and the mixture was allowed to equilibrate to room temperature. The silica gel was separated by filtration and extracted three times with dichloromethane (100 $\mathrm{mL}$ each portion). The combined organic layers were washed with dilute hydrochloric acid, saturated sodium bicarbonate solution and water (100 mL each) and dried over anhydrous sodium sulfate. The removal of dichloromethane with a rotary evaporator gave the raw product, which was purified by silica gel flash chromatography (ethyl acetate:hexane $=1: 5)$ to give $2.85 \mathrm{~g}(19.2 \mathrm{mmol}, 74 \%$ yield) of ${ }^{15} \mathrm{~N}$-4-nitro-4-methyl-1-pentanal. The $\mathrm{r}_{\mathrm{f}}$ value was determined to be 0.29 . The product was stored under argon at $-20{ }^{\circ} \mathrm{C} .{ }^{1} \mathrm{H}-\mathrm{NMR}\left(\mathrm{CDCl}_{3}\right): 1.58(\mathrm{~m}, 6 \mathrm{H}), 2.22(\mathrm{bt}, 2 \mathrm{H}), 2.49(\mathrm{t}, J=7.2 \mathrm{~Hz}, 2 \mathrm{H})$, $9.75(\mathrm{~s}, 1 \mathrm{H})$.

${ }^{15} \mathrm{~N}$-5,5-Dimethyl-1-pyrroline $\mathrm{N}$-oxide. In a $500 \mathrm{~mL}$ three-neck flask with an addition funnel, ethanol $(95 \%, 60 \mathrm{~mL})$ was cooled to $2{ }^{\circ} \mathrm{C}$. Then ${ }^{15} \mathrm{~N}$-4-nitro-4-methyl-1-pentanal (2.85 g, $\left.19.2 \mathrm{mmol}\right)$ and zinc dust ( $2.68 \mathrm{~g}, 0.41 \mathrm{mmol}, 2.1$ equivalents) were added. Under brisk magnetic stirring, glacial acetic acid $(4.2 \mathrm{~mL})$ was added dropwise while the temperature was kept below $10{ }^{\circ} \mathrm{C}$. After stirring $1 \mathrm{~h}$, the apparatus was put in a refrigerator suitable for flammable materials. Any hydrogen gas which may have formed was allowed to dissipate. After an additional $30 \mathrm{~h}$ of stirring at $10{ }^{\circ} \mathrm{C}$, the solution was filtered to remove zinc and any undissolved zinc acetate. The filtrate was extracted with cold ethanol $(3 \times 100 \mathrm{~mL})$. From the combined solutions, the ethanol was removed with a rotational evaporator. The residue was diluted with dichloromethane $(200 \mathrm{~mL})$ and washed twice with saturated sodium bicarbonate solution and water $(50 \mathrm{~mL}$ each). The organic layer was dried with magnesium sulfate, filtered and the dichloromethane removed with a rotary evaporator to give a reddish-brown crude product. The product was purified by two consecutive sublimations ( 0.1 torr) from room temperature to $0{ }^{\circ} \mathrm{C}$, and $305 \mathrm{mg}(2.7 \mathrm{mmol}, 15 \%)$ of ${ }^{15} \mathrm{~N}$-DMPO was obtained. ${ }^{1} \mathrm{H}-\mathrm{NMR}\left(\mathrm{CDCl}_{3}\right): 1.42(\mathrm{~m}, 6 \mathrm{H})$, $2.12(\mathrm{td}, 1.5 \mathrm{~Hz}, 7.6 \mathrm{~Hz}, 2 \mathrm{H}), 2.56(\mathrm{~m}, 2 \mathrm{H}), 6.80(\mathrm{t}, J=2.6 \mathrm{~Hz}, 1 \mathrm{H})$.

\subsection{Synthesis of 5,5-Di-(trideuteromethyl)-1-pyrroline $N$-oxide}

2-Nitropropane (D7). Urea (26.5 g, $0.44 \mathrm{~mol})$, and phloroglucinol (21 g, $0.17 \mathrm{~mol})$ were dissolved in dry $N, N$-dimethylformamide $(600 \mathrm{~mL})$ in a $1000 \mathrm{~mL}$ three-neck flask equipped with a magnetic stir bar, septum, Ar supply and bubbler, under an Ar atmosphere. Then, $\mathrm{NaNO}_{2}$ (24.74 g, $\left.0.36 \mathrm{~mol}\right)$ was added and dissolved. Heptadeutero-2-bromopropane (20 g, $154 \mathrm{mmol}$ ) was added, and the solution was stirred for $48 \mathrm{~h}$ at room temperature. The reaction was quenched with ice water $(1000 \mathrm{~mL})$ covered with diethyl ether $(200 \mathrm{~mL})$. The organic layer was separated and collected, and the aqueous layer was extracted four times with diethyl ether $(100 \mathrm{~mL}$ each). The combined organic layers were 
washed with saturated sodium bicarbonate solution $(100 \mathrm{~mL})$ and water $(2 \times 100 \mathrm{~mL})$. The organic layer was dried over anhydrous magnesium sulfate and filtered. The solvent was removed with a rotational evaporator to obtain the crude product. The product was purified by vacuum distillation $\left(-80 \mathrm{kPa}, 75^{\circ} \mathrm{C}\right)$ to give $4.02 \mathrm{~g}(42 \mathrm{mmol}, 27 \%)$ of 2-nitropropane (D7).

4,4,4-Trideuteromethyl-4-nitro-5,5,5-trideuteropentanoic acid methyl ester. The ester was synthesized from 2-nitropropane (D7) (4.02 g, $42 \mathrm{mmol})$, dioxane $(5 \mathrm{~mL})$, Triton B (1 mL) and methyl acrylate $(4.1 \mathrm{~mL})$ as described earlier for ${ }^{15} \mathrm{~N}-4-$ methyl-4-nitropentanoic acid methyl ester. The yield was

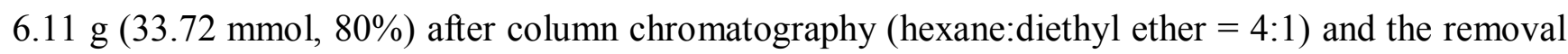
of the solvent. ${ }^{1} \mathrm{H}-\mathrm{NMR}\left(\mathrm{CDCl}_{3}\right): 2.26(\mathrm{~m}, 2 \mathrm{H}), 2.32(\mathrm{~m}, 2 \mathrm{H}), 3.67(\mathrm{~s}, 3 \mathrm{H})$.

4-Nitro-4,4,4-trideuteromethyl-5,5,5-trideutero-1-pentanal. The aldehyde was synthesized as described for ${ }^{15} \mathrm{~N}-4$-nitro-4-methyl-1-pentanal with dry dichloromethane $(200 \mathrm{~mL})$, the deuterated nitromethylpentanoic acid methyl ester $(6.11 \mathrm{~g}, 33.72 \mathrm{mmol})$ and a $1 \mathrm{M}$ stock solution of diisobutylaluminum hydride $(37.1 \mathrm{~mL})$ using water-free chemicals under an argon atmosphere. After flash chromatography (hexane:ethyl acetate $=5: 1)$ and removal of the solvent, $2.86 \mathrm{~g}(19.67 \mathrm{mmol}$, $58 \%)$ of the pure product was obtained. ${ }^{1} \mathrm{H}-\mathrm{NMR}\left(\mathrm{CDCl}_{3}\right): 2.14(\mathrm{t}, J=7.4 \mathrm{~Hz}, 2 \mathrm{H}), 2.42(\mathrm{t}, 7.4 \mathrm{~Hz}$, 2H), 9.67 (s, 1H).

5,5-Di(trideuteromethyl)-1-pyrroline $N$-oxide. The DMPO analog was synthesized similarly to ${ }^{15} \mathrm{~N}-5$,5-dimethyl-1-pyrroline $\mathrm{N}$-oxide, using ethanol $(100 \mathrm{~mL})$, the aldehyde intermediate (4.08 g; $19.67 \mathrm{mmol}$ ), zinc dust (3.69 g, $56.43 \mathrm{mmol}, 2.9 \mathrm{eq})$ and acetic acid (6.75 g, $112.4 \mathrm{mmol})$. Purification gave $357 \mathrm{mg}(2.75 \mathrm{mmol})$ of colorless DMPO crystals $(14 \%$ yield $) .{ }^{1} \mathrm{H}-\mathrm{NMR}\left(\mathrm{CDCl}_{3}\right): 2.12$ (td, $1.5 \mathrm{~Hz}, 7.6 \mathrm{~Hz}, 2 \mathrm{H}), 2.56(\mathrm{td}, 2.5 \mathrm{~Hz}, 7.4 \mathrm{~Hz}, 2 \mathrm{H}), 6.82(\mathrm{t}, J=2.5 \mathrm{~Hz}, 1 \mathrm{H})$.

ESR spectroscopy. We used a microwave frequency of $9.78 \mathrm{GHz}$ (X-Band), a microwave power of $20 \mathrm{~mW}$ and $1 \times 10^{4}$ receiver gain, a modulation frequency of $100 \mathrm{kHz}$ and modulation amplitude of $1.0 \mathrm{G}$. Time constant and conversion time were $40.96 \mathrm{~ms}$. The field range was $80 \mathrm{G}$ with a center field of 3512 G. For the spin-trapping experiment, $100 \mathrm{mM}$ of the ${ }^{15} \mathrm{~N}$ - or di(trideuteromethyl)DMPO analog was mixed with $100 \mu \mathrm{M} \mathrm{FeSO}_{4}, 200 \mu \mathrm{M}$ diethylenetriaminepentaacetic acid and $200 \mu \mathrm{M}$ hydrogen peroxide. The phosphate buffer $(100 \mathrm{mM}, \mathrm{pH}=7.4)$ was treated with Chelex-100 to reduce metal contamination. In control experiments, the iron or $\mathrm{H}_{2} \mathrm{O}_{2}$ was omitted for comparison. The experiment was repeated with regular ${ }^{14} \mathrm{~N}-\mathrm{DMPO}$.

Mass Spectrometry. Samples of the DMPO analogs were initially prepared at $100 \mathrm{mM}$ in acetonitrile, diluted 1000 -fold just prior to analysis with a solution of water with $0.1 \%$ formic acid and infused into the mass spectrometer at $500 \mathrm{~nL} / \mathrm{min}$ using a syringe pump. The instrumental parameters for the MS analyses were as follows: capillary voltage, $3.5 \mathrm{kV}$; cone voltage, $30 \mathrm{~V}$; collision energy, $4 \mathrm{eV}$ and source temperature, $80{ }^{\circ} \mathrm{C}$. MS/MS data of the DMPO analogs were acquired using collision energies of $15-25 \mathrm{eV}$. For calibration, a solution of glu-fibrinopeptide B $(500 \mathrm{fmol} / \mu \mathrm{L})$ in water/acetonitrile $80: 20(\mathrm{v} / \mathrm{v})$ with $0.1 \%$ formic acid and a mass of $785.8496(2+)$ was used. Data analysis was accomplished using MassLynx software supplied by the manufacturer. 


\section{Conclusions}

Here we describe a synthesis pathway for the isotopically labeled spin traps ${ }^{15} \mathrm{~N}$-5,5-dimethyl-1-pyrroline $N$-oxide and 5,5-di(trideuteromethyl)-1-pyrroline $N$-oxide. Though syntheses for isotopically labeled DMPO have already been reported [8], the elimination of hydrogen gas and ozone as reactants and the respective special equipment facilitates the synthesis and gives reasonable yields. As reported previously [7], Michael reaction to the methyl ester and subsequent reduction to the aldehyde allows for better yields and easier purification compared to direct aldehyde formation. For reduction to DMPO, it may be beneficial to protect the aldehyde as the corresponding dioxolane first since the yield of the direct reaction was below the yield reported in the original paper. This issue has also been reported elsewhere [15]. Our approach is well suited for the synthesis of isotopically labeled DMPO analogs.

\section{Acknowledgments}

We would like to thank Ann G. Motten, Jean Corbett, Fiona A. Summers and Mary J. Mason for their help with the manuscript and Eugene DeRose for the NMR measurements. This research was supported by the Intramural Research Program of the NIH, National Institute of Environmental Health Sciences.

\section{References}

1. Janzen, E.G.; Blackburn, B.J. Detection and identification of short-lived free radicals by electron spin resonance trapping techniques (spin trapping). Photolysis of organolead, -tin, and -mercury compounds. J. Am. Chem. Soc. 1969, 91, 4481-4490.

2. Qian, S.Y.; Kadiiska, M.B.; Guo, Q.; Mason, R.P. A novel protocol to identify and quantify all spin trapped free radicals from in vitro/in vivo interaction of $\mathrm{HO}^{\circ}$ and DMSO: LC/ESR, LC/MS, and dual spin trapping combinations. Free Radic. Biol. Med. 2005, 38, 125-135.

3. Yu, Q.; Purwaha, P.; Ni, K.; Sun, C.; Mallik, S.; Qian, S.Y. Characterization of novel radicals from COX-catalyzed arachidonic acid peroxidation. Free Radic. Biol. Med. 2009, 47, 568-576.

4. Timmins, G.S.; Barlow, G.K.; Silvester, J.A.; Wei, X.; Whitwood, A.C. Use of isotopically labelled spin-traps to determine definitively the presence or absence of non-radical addition artefacts in EPR spin-trapping systems. Redox Rep. 1997, 3, 125-133.

5. Janzen, E.G.; Jandrisits, L.T.; Shetty, R.V.; Haire, D.L.; Hilborn, J.W. Synthesis and purification of 5,5-dimethyl-1-pyrroline- $N$-oxide for biological applications. Chem.-Biol. Interact. 1989, 70, 167-172.

6. Bonnett, R.; Brown, R.F.C.; Clark, V.M.; Sutherland, I.O.; Todd, A. Experiments towards the synthesis of corrins. Part II. The preparation and reactions of $\Delta$-1-pyrroline 1-oxides. J. Chem. Soc. 1959, 2094-2102.

7. Le, D.D.; Zhang, Y.; Nguyen, D.; Moravek, J. Synthesis of 5,5-dimethyl-1-pyrroline-N-oxide-2- ${ }^{14}$. J. Labelled Comp. Radiopharm. 2000, 43, 1107-1111.

8. Pou, S.; Rosen, G.M.; Wu, Y.; Keana, J.F.W. Synthesis of deuterium and ${ }^{15} \mathrm{~N}$-containing pyrroline 1-oxides: A spin trapping study. J. Org. Chem. 1990, 55, 4438-4443. 
9. Kornblum, N.; Larson, H.O.; Blackwood, R.K.; Mooberry, D.D.; Oliveto, E.P.; Graham, G.E. A new method for the synthesis of aliphatic nitro compounds. J. Am. Chem. Soc. 1956, 78, 1497-1501.

10. Zhang, H.; Joseph, J.; Vasquez-Vivar, J.; Karoui, H.; Nsanzumuhire, C.; Martasek, P.; Tordo, P.; Kalyanaraman, B. Detection of superoxide anion using an isotopically labeled nitrone spin trap: Potential biological applications. FEBS Lett. 2000, 473, 58-62.

11. Bonnier, M.; Marsura, A.; Luu-Duc, C. Synthesis of 2,4-diphenyl-5-ethoxycarbonyl-1heptadeuterated isopropyl-2-imidazoline. J. Labelled Comp. Radiopharm. 1986, 23, 67-71.

12. Moffett, R.B. Methyl $\gamma$-methyl- $\gamma$-nitrovalerate [valeric acid, 4-methyl-, 4-nitro-, methyl ester]. Org. Synth. 1952, 32, 86-87.

13. von Gersdorff, J. Über Cyclohexylen-Verbrückte Porphyrin-Chinone als Modellverbindungen zur Untersuchung der Photoinduzierten Ladungstrennung in der Photosynthese; Freie Universitaet: Berlin, Germany, 1991.

14. Haire, D.L.; Hilborn, J.W.; Janzen, E.G. A more efficient synthesis of DMPO-type (nitrone) spin traps. J. Org. Chem. 1986, 51, 4298-4300.

15. Rosen, G.M.; Britigan, B.E.; Halpern, H.J.; Pou, S. Free Radicals: Biology and Detection by Spin Trapping; In Oxford University Press: New York, NY, USA, 1999; pp. 188-190.

16. Jiang, J.J.; Jordan, S.J.; Barr, D.P.; Gunther, M.R.; Maeda, H.; Mason, R.P. In vivo production of nitric oxide in rats after administration of hydroxyurea. Mol. Pharmacol. 1997, 52, 1081-1086.

17. Wertz, J.E.; Bolton, J.R. Electron Spin Resonance: Elementary Theory and Practical Applications; McGraw-Hill: New York, NY, USA, 1972.

Sample Availability: Small samples of the compounds are available from the authors.

(C) 2011 by the authors; licensee MDPI, Basel, Switzerland. This article is an open access article distributed under the terms and conditions of the Creative Commons Attribution license (http://creativecommons.org/licenses/by/3.0/). 